\title{
LA FATIGA DEL MODERNO
}

\author{
Riccardo Caporali \\ (Universidad de Bolonia)
}

RESUMEN: Vico es un moderno "excéntrico": toda su filosofía aparece atravesada por una instancia civil que, diversamente declinada, sostiene firmemente el problema -al mismo tiempo crucial e irresoluble- del principio del orden político.

Palabras Clave: G. Vico, $350^{\circ}$ Aniversario, modernidad, filosofía política, R. Caporali.

\section{The fatigue of the modern}

ABSTRACT: Vico is a modern "eccentric": his entire philosophy is crossed by a civil authority that, in various declinations, firmly supports the problem — both crucial and unsolvable — of the principle of political order. KEYwords: G. Vico, $350^{\text {th }}$ Anniversary, modernity, political philosophy, R. Caporali.

\section{La fatica del moderno}

RiASSUNTO: Vico è un "eccentrico" moderno: tutta la sua filosofia è attraversata da un'istanza civile che, seppur declinata in vario modo, sostiene fermamente il problema - al tempo stesso cruciale e irrisolvibile - del principio dell'ordine politico.

PAROLE CHIAVE: G.Vico, 350 anniversario, modernità, filosofia politica, R. Caporali.

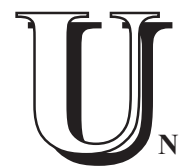

N GENIO O UN IMBÉCIL

Mi primer contacto con Vico se remonta a mis años de estudiante en la Universidad de Bolonia. En sus cursos de historia de las doctrinas políticas, Guido Fassó no dejaba nunca de hacer referencia al filósofo napolitano. Con aquella actitud cautivadora y poco formal que lo caracterizaba, la premisa de sus consideraciones aparecía como decididamente provocadora: «Vico o es un genio, o es un imbécil». Naturalmente, sus lecciones se encargaban de demostrar que el autor de la Scienza nuova no podía constreñirse a la imagen de un filósofo ingenuo o retrasa-

Este artículo responde a una invitación expresa por parte de la Dirección de la Revista para este volumen especial por el $350^{\circ}$ Aniversario del nacimiento de G. Vico, habiendo superado los criterios de valoración y del proceso de aceptación. 
do; y también que era imposible etiquetarlo según los esquemas demasiado simplificadores del "precursor" de alguien o de algo. El mismo planteamiento de Fassó, a la larga, acabó por parecerme indiscutible, especialmente en su polémica defensa de la prioridad del verum-certum respecto al verum-factum, que me pareció demasiado inspirada por instancias "conservadoras" (demasiado preocupada por los movimientos de la autoridad, más que por los que la autoridad instituye y continuamente pone en discusión) e incluso limitada por la asunción implícita -compartida por otros muchos, no solo Fassó- por la cual esos binomios conceptuales, aunque diversamente declinados en la multiforme producción teórica viquiana, deberían reconducirse de todos modos hacia presupuestos de naturaleza exquisitamente metafísica. Las lecciones de Fassó, en cualquier caso, me abrieron al mundo para mí sorprendente de un verdadero clásico, cuya fortuna no se había ahorrado muchas y muy opuestas interpretaciones: idealistas, ilustradas, católico-ortodoxas, marxistas, "hermenéuticas".

\section{LA POLÍTICA}

Cuando, en los años Ochenta, comencé a investigar de verdad sobre Vico, la hegemonía de la interpretación neoidealista crociana se había agotado desde hacía tiempo, suplantada por una ingente mole de sondeos en Italia y en el mundo, a menudo orientados a revalorizar aquellos aspectos del pensamiento viquiano -comenzando por la política y la retórica- que Croce había descuidado, relegándolos al gueto de la divagación y de la "confusión", perturbaciones meramente empíricas de la esencia del filósofo napolitano, genial pero aproximadamente precursoras del idealismo. Por intereses personales, para nada extraños al espíritu general del momento, me interesaba sobre todo la política, que algunos aguerridos estudiosos italianos -en particular Nicola Badaloni, Biagio De Giovanni, Giuseppe Giarrizoya desde finales de los años cincuenta se habían encargado (cada cual desde sus peculiares perspectivas) de sacar a la luz como una dimensión esencial del pensamiento viquiano, en oposición a la representación crociana del autor de la Scienza nuova como "alma bella", alejada de los problemas de su época.

El punto de partida metodológico de los tres autores era común: en abierta alternativa frente al Vico apolítico de Croce, estaban buscando las influencias del tempo politico de Vico sobre su filosofía; es decir, investigaban si y cómo él fue partícipe en cierto modo, en el plano de la elaboración teórica, de los acontecimientos sociopolíticos napolitanos entre el siglo XVII y el XVIII. Quiero recordar cómo esta crítica historiográfica resultaría perfectamente acorde con el denominado "nuevo curso" de los estudios viquianos, que en Vico nel suo tempo se afirmó como un propio y constante motivo conductor. En el caso de la política, sin embargo, me parece que surgen al menos dos órdenes de problemas: en el plano metodológico general, las dificultades derivadas de una crítica conjunción de 
acontecimientos históricos y categorías filosóficas resultan enormes, tanto como para constreñir el análisis a la delgada frontera que separa agudas intuiciones y esquematismos reduccionistas; en cuanto al plano específico del pensamiento viquiano, si la vía parece de algún modo transitable en sus primeras fases, en virtud de algunas problemáticas (piénsese en la relación política-cultura en las Orationes) particularmente compatibles con este tipo de investigación, las dificultades estallan insuperables con las obras mayores, especialmente con la Scienza nuova, donde los ecos de la época se hacen mucho más lejanos y vagos. De ahí la necesidad, para los intérpretes, de insertar un rígido coupure en la política en Vico: o replegando el Diritto Universale y la Scienza nuova al momento "defensivo" y "restaurador" (la vía practicada por Giarrizzo, con todos los problemas que surgen al relegar a este papel las diversas redacciones de su principal obra); o presumiendo el paso de un compromiso ideológico-político más directamente ligado a su tiempo (por la superación de las persistentes estructuras feudales en el virreinato de Nápoles, y por su renovación a través del derecho), a una reflexión teórica general, de la que la política restaría como fuente animadora solo indirecta. Fue esta última la vía utilizada por Badaloni y, sobre todo, por De Giovanni: al Vico intelectual políticamente comprometido de las primeras obras, habría seguido el Vico moderno filósofo de la política. Al Vico biográfica y filosóficamente extraño a la política de Croce acababan así por contraponerse otras y nuevas síntesis teóricas: el Vico "preilustrado" de Badaloni, el Vico "dialéctico" de De Giovanni. Se trataba -para evitar equívocos- de contribuciones preciosas e innovadoras, capaces de alumbrar muchos aspectos de la filosofía viquiana antes olvidados. Y, sin embargo, con la limitación de proponerse como unas síntesis teóricas probablemente demasiado amplias, todas legitimas y todas discutibles. En la alternativa sin variantes de política de su tiempo (primeras obras) y actualizante filosofia política (obras mayores), me parecía que se alimentaba una dificultad historiográfica real: la de dejar abierta la oportunidad de una articulada y directa investigación sobre el efectivo puesto de la política en las páginas de la Scienza nuova.

Cualquiera que sea su efectiva consistencia, mi primera monografía sobre Vico (Heroes gentium. Sapienza e politica in Vico, de 1992) intentaba responder a esta exigencia, también con la escolta de una preciosa indicación de Pietro Piovani que, en uno de tantos ensayos publicados en torno al tercer centenario del nacimiento de Vico, sugería condensar la política en torno a un núcleo fundamental, capaz «sin alteración» de «dar la vuelta a toda la filosofía viquiana» y de delinear, sobre la base de «sus mismos caminos, un diseño interpretativo nuevo». Me pareció poder divisar este lugar de reconocimiento global del elemento político de Vico en la historia de Roma, recurrente punto de confluencia de los intentos de conjunción de la "sabiduría" y de la "política" (de la filosofía y de la filología, de lo verdadero y de lo cierto). Analizado desde este ángulo prospectivo, el pensamiento de Vico se pre- 
senta, quizá inesperadamente, bajo el signo de marcadas, de atormentadas discontinuidades. Por decirlo sintéticamente:

I. Hasta el De antiquissima toda la investigación teórica de Vico, aun en la variedad de temas e impostaciones, está animada por el propósito de fundamentar la política sobre la sabiduría, siguiendo una línea esencialmente tardo-humanista, en cuya dirección confluyen incluso motivos galileanos y baconianos, platonizantes y cartesianos. La sabiduría -conocimiento de las res altissimae, del aeternum verum que impone el equilibrio, el control de los sentidos y del cuerpo- legitima la política como ejercicio de aquellas virtudes morales (iustitia, moderatio, temperantia, clementia) que permiten regularizar, normalizar las relaciones entre los hombres; permiten exorcizar los conflictos haciendo prevalecer la razón (los derechos).

II. Un sondeo en el De rebus gestis Antonii Caraphaei (trabajo muy a menudo relegado al recinto crítico-historiográfico de las investigaciones archivísticas y de las curiosidades eruditas) sobre la base del binomio conceptual "sabiduría-política" produce resultados sorprendentes, porque las posiciones aparecen aquí invertidas con respecto a la fase precedente: la política no se aprende a partir del summum verum de la sabiduría, sino que se ejercita por la instintividad del carácter, que sabe seguir mejor la velocidad de la acción; los Estados surgen del conflicto de las fuerzas y de las armas y solo "después" y "dentro" de este espacio fundacional pueden progresar gracias a las artes liberales y a las leyes; es fuerte ese Estado que sabe mantener rico a lo público y pobre a lo privado; al caos de la fortuna el hombre puede oponer una virtus ordenadora pero trágica, porque en última instancia está destinada a ser arrollada por los acontecimientos. Para quebrantar la lineal superioridad de la sabiduría sobre la política emergen elementos de clara matriz maquiaveliana. $\mathrm{Y}$ en el origen de esta crisis se agita una asimismo atormentada investigación sobre la virtus de los Romanos, que parece cada vez menos alimentada por el conocimiento y por la práctica de las dignae artes, porque se caracteriza cada vez más como vis primitiva y bárbara, como fuerza de la ignorantia.

III. En el Diritto Universale los temas de lo "primitivo" y del "conflicto" se incluyen en el seno de un grandioso proyecto metafísico, que se presenta, no sin altivez, como "sistema de derecho natural" coherente con los principios de la religión católica, en respuesta a la gran especulación filosófico-jurídica de la Europa reformada. Identificado lo "primitivo" con lo "ferino", con el momento de la caída del hombre desde la integridad de su naturaleza originaria, a consecuencia del pecado de Adán, una enorme teología histórica del derecho reporta lentamente a la humanidad hacia la reconquista de su propia esencia divina-racional. El Estado, la auctoritas civilis, se configura en este contexto como experiencia decisiva, en cuanto que es la más amplia articulación ordenada de dominium, libertas y tutela, los derechos "naturales" primarios y constitutivos del hombre. En su equilibrio -garantizado por las formae mixtae, atemperadas, del imperium - está el máximo de virtus 
política y el punto más alto de aproximación a la naturaleza del Adán incorrupto. En Roma el conflicto entre patres y plebs alimenta continua y sinérgicamente las instancias de dominium, libertas y tutela, evitando los excesos desequilibrantes. Los Romanos fueron por ello heroes Gentium, pudieron unificar políticamente el mundo y consentir así el pleno desarrollo del derecho natural. El tema maquiaveliano -y campanelliano- de la lucha entre patricios y plebeyos como causa primaria de la grandeza de Roma se complica, pues, "desde la base", en cuanto que se reviste desde el inicio de virtud y juridicidad (sobre el fondo, juntos, los glosadores y la Monarquía de Dante), para ser luego resuelto hasta el vértice, en la perspectiva escatológica del advenimiento del Cristianismo como cumplimiento de la verdadera sabiduría sobre la tierra: impregnado de filosofía griega, de derecho romano y de religión cristiana, el Corpus iuris justiniano es la sabiduría (civil) depuesta para siempre, puesta eternamente "a disposición" de la humanidad. El mundo moderno salió de la oscuridad de la barbarie medieval reedificándose sobre estos eternos principios.

IV. A través de las distintas redacciones de la opus maius, aún otra diferente sistematización "filológica" de la historia de Roma (de las figuras y de los momentos de la historia romana que más atormentan la investigación de Vico: de la fundación del censo serviano, de la reforma de Bruto a las XII Tablas) desvela una naturaleza de la política diversa: el Estado romano es desde el comienzo una mera respublica optimatium; su grandeza reside totalmente no en la publica virtus, alimentada por los contrastes internos entre las partes, sino en el vicio privado, en el férreo dominio de los patres sobre la plebs. El "descubrimiento" parte del mundo aristocrático-heroico de Roma, pero termina implicando también a la estructura del tiempo humano "desplegado", ese mundo moderno de la "completa humanidad" en cuya forma monárquica la más amplia libertad natural se funda sobre la más intensa restricción del poder, el máximo de razón e igualdad sobre la máxima concentración de fuerza. Sabiduría y derecho no regulan la relación política, sino que están dentro de ello: una discusión analítica de las "fábulas" y de su interpretación en la Scienza nuova muestra cómo el papel de la sabiduría se pone ahora por entero bajo el control de los vínculos de dominio. El «sistema metafísico», universalizante y escatológico del Diritto Universale deja entonces el campo al ricorso, impasible certeza de la conservatio, de la pura persistencia física de la humanidad, incluso en los momentos de crisis irrefrenables y de refundaciones imprevisibles, de enormes fracturas y de lentas, complicadas, recomposiciones.

\section{UN MODERNO EXCÉNTRICO}

En Vico operan, a la vez, la neta caracterización de la superioridad de lo moderno y la sensibilísima percepción de sus contradicciones fundacionales, de sus tensiones constitutivas. 
Siempre me pareció un primer ejemplo significativo de la modernidad de Vico el de las relaciones entre historia sagrada e historia profana en la Scienza nuova. Como se sabe, el filósofo napolitano mantiene separadas las «dos historias»: por una parte el tiempo único, totalmente humano y lineal de los Hebreos, vigilado por la divinidad (sostenido por los milagros, por las «ayudas extraordinarias» del «verdadero» Dios); por otra parte los tiempos mutables de la humanidad gentil, el «curso de las naciones», el tortuoso camino de los otros pueblos, acompañados por las «únicas ayudas ordinarias de la providencia» (de una peculiar constitución de la «común naturaleza» de los hombres). Una elección semejante parece, de entrada, totalmente tradicional, respecto a las conclusiones opuestas y subversivas a las que ya tantos habían llegado antes de Vico, entre Spinoza y Fréret. Pero el modo específico en el que él utiliza esta separación es en realidad funcional para una más libre indagación de la ciencia, incluso en su opinión sobre la religión, en la función que la religión desempeña durante el proceso de civilización. La misma «verdadera religión» (el cristianismo) no deriva de la posibilidad de hacerse materia, objeto de la «nueva arte crítica», como parece evidente por el papel meramente civil que esta le reserva en la edad de la «barbarie retornada». Al contrario de lo que acontecía en el Diritto Universale, la historia profana no se disuelve y no se resuelve en la sagrada. Al culminar el curso de las naciones Vico no repropone la historia sagrada, sino los caracteres fundacionales de una época nueva.

Un segundo aspecto de la modernidad de Vico remite a la evidente superioridad de la última edad de las naciones, con respecto a las dos precedentes. Que gran parte de su obra principal se centre en el mundo oscuro y fabuloso y en la experiencia poética no anula este dato de hecho, que hace imposible cualquier lectura de la Scienza nuova bajo el signo de una suerte de frontal contraposición de su autor frente a la razón moderna. El método y el contenido del cuarto libro de la opus maius resultan emblemáticos a este propósito. Vico procede more sociologico, por aproximaciones temáticas tripartitas: tres "especies" de naturaleza, tres "especies" de costumbres, de derechos, de gobiernos, de lenguas, y así sucesivamente. Pero se trata, evidentemente, de un procedimiento irónico, hábil y consciente, que valora en el momento mismo en que relata. Bien sabe el profesor de retórica (primera de tantas exangües extenuaciones analíticas de hoy) cuánto de prescriptivo puede expresar la aparente asepsia de una exposición descriptiva. Solo dos ejemplos. Naturaleza: si la primera, «por fuerte engaño de la fantasía, la cual es robustísima en los muy débiles de raciocinio, fue una naturaleza poética, o sea, creadora, lícito es que se la llame divina, la cual a los cuerpos dio el ser de sustancias animadas», y la segunda fue la «heroica, tenida por esos héroes como de divino origen» (porque, «creyendo que todo lo hacían los dioses, se tenían como hijos de Júpiter, ya que habían sido generados con los auspicios de Júpiter»), la tercera fue «naturaleza humana, inteligente $\mathrm{y}$, por tanto, modesta, benigna y razonable, que reconoce por leyes la conciencia, la 
razón, el deber». Gobierno: teocráticos los primeros, «en los cuales los hombres creerían cualquier cosa que enviaran los dioses»; heroicos los segundos, es decir, «por distinción, de naturaleza más noble, porque se cree de origen divino»; «humanos» los terceros, en los cuales, "por la igualdad de esa inteligente naturaleza, que es la propia naturaleza del hombre, todos se igualan con las leyes». No existe traza de contactos «extraordinarios» con lo divino en esta representación de la «completa humanidad»; no existe traza de diálogo, de relación directa entre Dios y las naciones, en el apogeo de su transcurso; no existe traza ni de milagros ni de fundamentos teológicos en la dinámica política que construye y sostiene dicho cumplimiento. Existe, a lo más, como se deduce obviamente de la insistencia sobre ese "creer" y sobre ese "ser" que enervan por antítesis toda la estructura de este libro, la idea del transcurrir necesario-providencial de las naciones desde un orden compacto y heterónomo, fundamentado esencialmente en la subordinación supersticiosa y autoritaria (en el considerarse en manos de la divinidad, en la fuerza-superioridad que deriva del creerse amados por Júpiter) hasta un orden implantado autónoma-mente en la humana potencia, a través del pleno desarrollo racional de libertad e igualdad, «la propia naturaleza del hombre».

Un tercer efecto de la modernidad de Vico se recoge, pues, en su propia crítica a la modernidad que resultará, por así decir, teóricamente prevalente e históricamente vencedora. Su reflexión mantiene firmemente el problema de la naturale$z a$, del origen del proceso de civilización. Donde el racionalismo a lo Hobbes deslegitima el comienzo de lo político reduciéndolo a la insostenible, amenazante inconsistencia del «estado de naturaleza», Vico sostiene firmemente el problema crucial del principio del orden político, junto a la potencia y amenaza de todo su desarrollo. Donde el "contrato" (la más relevante adquisición del constructivismo racionalista, de Hobbes a Kant) se expresa en el interior de esa lógica de pura funcionalidad del Estado que tiene definitivamente arrinconado el núcleo -irreductible a regla, a ley, a sustancia - de su fuente, el pensamiento de Vico no se aleja del vórtice abismal de la génesis de lo político. Una exigencia y casi un ansia teórica que, sin embargo, mantiene firmes las instancias críticas (en todo caso racionales) de la ciencia, sin vuelta atrás, hacia los fundamentos naturales del paganismo, o hacia aquellos teólogos de la cultura cristiano-medieval. Ningún romanticismo político en Vico. El magma del principio se recoge en la dimensión oscura y nunca definitivamente controlable de su conflictividad. Con la desaparición de todo fundamento externo, lo irregular, lo irreductible, en la génesis de lo político, acaba por reunirse en su instancia inevitablemente agonística multitudinaria; es la "fatiga" de los fámulos (las «multitudes de los pueblos», las «catervas de los jornaleros») el motor del curso de las naciones. No por casualidad, a la entrada y a la salida del máximo nivel de la potencia humana se localizan las repúblicas populares, cuya fuerza extraordinaria (la igualdad de razones y de derechos) corresponde también a su más peli- 
grosa amenaza, en el riesgo permanente de la pérdida de todo «sentido común» de las «comunes utilidades», en el repliegue egolátrico e insensato de una razón estéril y reseca, «monástica» e instrumental, que pierde la esencia vital de las relaciones (del cuerpo, del sentimiento, de la pasión).

$\mathrm{Y}$ es precisamente por esto, en definitiva, por lo que la ciencia «no concluye». La «historia ideal eterna, sobre la cual transcurren las historias de todas las naciones» permanece en realidad como un problema abierto, una tensión nunca circunscrita a los recintos de claras y definitivas armonías. El «círculo» en el cual la ciencia se esfuerza por encerrar a la política no parece, en última instancia, mucho más que una metáfora geométrica, rota como está, en realidad por la enorme tarea del ricorso: no el nexo entre una crisis y su (dialéctica) superación, sino la última catástrofe de las naciones. Lejos de poder reducirse a una actitud psicológica del investigador, el trabajo inagotable de la glosa, del comentario, de la adenda, responde a esta profunda exigencia crítica. Emblemáticamente simétrica -por lo menos en el plano semántico- a la de los fámulos, la "fatiga" de la investigación termina solamente con el final del investigador.

Analizada al tamiz de la política, la nueva ciencia se abre así, paradójicamente, a una instancia hipermoderna. Y quizá es también por esto por lo que, ya en el ocaso de una forma política junto a la cual -justo viquianamente- parece atardecer una época entera, las páginas directas y profundas de la Scienza nuova continúan interrogándonos y fascinándonos.

[Traducción del italiano por María José Rebollo Espinosa]

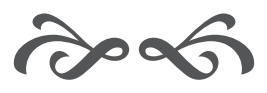

